\title{
Key factors affecting disposal of radioactive waste in the sustainable development approach
}

\author{
Adrian TANTAU \\ Bucharest University of Economic Studies, Bucharest, Romania \\ adrian.tantau@fabiz.ase.ro \\ Greta-Marilena VITIOANU \\ Bucharest University of Economic Studies, Bucharest, Romania \\ vitioanu.greta@yahoo.com
}

\begin{abstract}
The radioactive waste disposal is a well investigated issue worldwide because of its importance for a safe and sustainable use of nuclear energy. Such waste is subject to final storage in deep geological disposals. Many factors have a direct contribution to the success of such innovative facility. The objective of the study is to identify the principal factors which contribute to the radioactive waste location. Factors that influence public acceptance are recognized and emphasized in the paper. The methodology is based on a questionnaire for empirical data obtaining and interviews with a selected group of experts to explore the insights of a disputed topic. The study reveals the quantitative analysis of the key factors as wellestablished contributors for understanding how and where to construct a radioactive waste facility. General information about the respondents was considered, as well as the possibility and the level of cooperation with stakeholders, the degree of information and the motivation of the given benefits as important influential factors over location and construction of a radioactive waste disposal. Overall, the study has shown that various factors influence the general public attitude, and this aspect leads to a direct influence on the location and construction of such a facility. The novelty of the research consists in key factors investigation that specially influence the location and the construction of a radioactive waste disposal, especially because the available literature studies in this area are not so strong developed yet.
\end{abstract}

Keywords: radioactive waste, sustainable development, disposal, key factors, radioactive waste management, public acceptance, perceived risk, nuclear energy.

\section{Introduction}

At international level, disposal of radioactive waste is a problem that encompasses a lot of debates between experts which try to find sustainable solution for disposing of this waste.

Radioactive waste is a category of waste that remain hazardous for thousands of years and generates huge payments for its treatment and disposal.

Radioactive waste represents the secondary products of nuclear technologies. Over time, many industries were developed based on nuclear technologies, as energy production, medicine, research, agriculture, food preservation or even defense.

Spent nuclear fuel, as a product of energy generation, may be stored for a specific amount of time in water-filled pools and afterwards in special containers at the same location where it is produced or close to that facility and, after an initial cooling period may be reprocessed and recycled. In such case, spent nuclear fuel is treated as a valuable resource.

The reprocessing of spent nuclear fuel is a process which gives the possibility to recover reusable materials, such as Uranium and Plutonium for future new fuel. Unfortunately, reprocessing of spent nuclear fuel involves highly costs and also generates important quantities of radioactive waste (Choi, 2016). 
For a long-term disposal, the spent nuclear fuel, if treated as waste, has to be transported to a specialized facility. Normally, before transportation the storage period in interim facilities for cooling and decreasing of the radioactivity is required (e.g. 20 years).

Regardless the strategy adopted by countries, reprocessing and recycling or either direct disposal, both approaches involve deep geological facilities.

After Fukushima disaster in 2011 countries like Japan and Germany, took the political PICBE $\mid 2$ decision to close their nuclear reactors, action which helps also to achieve a more sustainable environment. Even in such conditions the generated radioactive waste has to be well managed and properly disposed of in special locations, in order to speak about a safety and environmentally friendly process.

From a business perspective, radioactive waste is characterized by highly expensive management due to the large time period over which the secure disposal is necessary (Beken, 2010).

The process for disposing of nuclear waste has to be designed not only from a technical point of view but, it has also to take into account the perceptions, beliefs and other important values of different stakeholders. Technical factors play important roles, but great importance must also be attributed to the economic, politic and social factors, both at national and international levels, as the experience of many countries over time has shown. Public support is one of the key issues considered when radioactive waste strategies are elaborated.

Disposing of radioactive waste with no retrieval intention is also part of the sustainable development approach because it does not involve technical or future hurdle for future generations.

All these factors are playing important roles in the process of establishing the disposal location for the radioactive waste.

Considering all aspects emphasized in this section, the major objective of this paper is to identify the key factors which contribute to the radioactive waste location.

\section{Literature review}

Scientific studies argued that deep geological disposal facilities are the most suitable solution for long term radioactive waste disposal (Rempe, 2007). For safety reasons for people, deep geological disposals have to be built 500-1000 m below the surface, which have old and stable rocks laying at large depths. Multi-barrier systems need to be implemented for isolating the radioactive waste. Such systems are a combination between natural geological barriers and engineered barriers (Streimikiene, 2012). In practice, geological restriction, technical requirements and socioeconomic factors are important barriers for implementing deep geological disposals.

In the category of socioeconomic factors which influence the radioactive waste location is found the public perception with a key role. This perception can be seen as a risk perception, when any hazard to which people are or might be exposed is analyzed or as a benefit perception, when people are thinking on the associated benefits. The benefits are represented by important economic achievements, such as new jobs for several years for building the new disposal facility and significant investments for the disposal facility but also in the region (Segelod, 2006; Ramana, 2013; Yano, 2018).

However, the risk perception is different at women, which identify, in general, more risks than men (Stefanelli et al., 2017). 
An effective communication policy can reduce the risk perception for the radioactive waste disposal and the policy acceptance can be gained more rapidly, if this is based on viable arguments that may increase also the benefits perception. It is well known that people are concerned about risk and they must feel safe and secure. During time was remarked that communities show a positive opinion if they already are the host of a nuclear facility. Researchers identified that understanding the factors which influence public reactions to risks is a very important aspect. A particular activity or technology may have specific benefits for society, but it could be not equally for individuals.

Essential questions will be beneficial in special cases where radioactive waste disposing involve the society. Where should the radioactive waste be disposed of, close to the nuclear facility in intense populated areas and where individuals and their families could have substantial benefits from the technology developed in that area? Should the radioactive waste be disposed of in wild areas where human life is not propitious?

Accepting a nuclear facility in the backyard is not an easy task. Not in my backyard (NIMBY) is a real phenomenon and a complex issue because many explanations are required. A diverse range of factors should be taken into consideration. This phenomenon arises especially in case of facilities perceived as dangerous or noxious. Many theoretical and empirical studies addressed NIMBY in order to reveal the factors that lead to such perceptions. NIMBY was found especially in the energy sector, but not only in case of nuclear energy, but also in case of biomass plants or wind farms (Devine-Wright, 2011).

The main risk factor that is associated with the radioactive waste is the human risk. Another specific factor related to the risk of disposal of radioactive waste is the environmental risk such as soil or water pollution. Studies indicate that radioactive waste seems to be much more dangerous compared to other waste categories due to the fact that it is strongly associated with nuclear power and even with nuclear weapons (Moser et al., 2013).

Another main specificity for the placement of a radioactive waste disposal is that it represents a local solution to a national or even global problem (Lehtonen et al., 2020). Therefore, the state represents also a key factor for establishment of a disposal location for highly radioactive waste.

\section{Methodology}

The main objective of the study was to identify the key factors which contribute to the location of a radioactive waste facility.

During the period of 2019 and 2020, questionnaires were distributed to people from different regions of Romania. The questionnaire was structured in three main parts, first one sketched the respondents' profile, second one was focused on finding answers to general questions regarding respondents attitudes to nuclear power, their images to nuclear power and their support for a radioactive waste disposal facility, while the third one was focused more on finding the level of information and knowledge of the respondents in regard with nuclear technologies and nuclear concepts and which factors influence the radioactive waste disposal.

Respondents could access the questionnaire through Google forms or in printed format. The access link to the questionnaire was distributed online. The printed formats were distributed by the authors or by other collaborators. The respondents were not chosen based on specific criteria. Researchers only put efforts to have a uniform distribution of the respondents throughout the country. 
The respondents were thoroughly informed about the nature of the research and about the academic purpose. The purpose of the study was all the time available to all participants, this being written at the beginning of every questionnaire. No personal data was required however, the respondents were assured of the confidentiality of the answers.

The explanatory text does not contain influential information, objectivity in answers being very well maintained.

PICBE $\mid 4$

The entire questionnaire comprised in total 28 questions, but only some of them were used for this study.

Predictor variables used in this research questionnaire consisted of: socio-demographics, perceived affective quality of their images, perceived knowledge, perceived attitudes, social, psychological and economic support or opposition, perceived trust, perceived harm, risk perception, as well as opinions and attitudes to nuclear technology.

\section{Results and discussions}

The study results and the obtained data are presented. Demographic respondents' profiles in terms of age, gender, residency, employment status can be seen in the bellow figures, from no. 1 to no. 4. Figure no. 1 shows that the most respondents are divided with around $30 \%$ into 20 to 30 age group and over 45 age group. Not far from these two categories is the 31 to 45 category, with $28 \%$. It is essential to highlight that people who have decision-making capacity at the actual moment responded to the questionnaire. The future is influenced by the present taken decisions, so that next generations will have to manage the results of actual decisions.

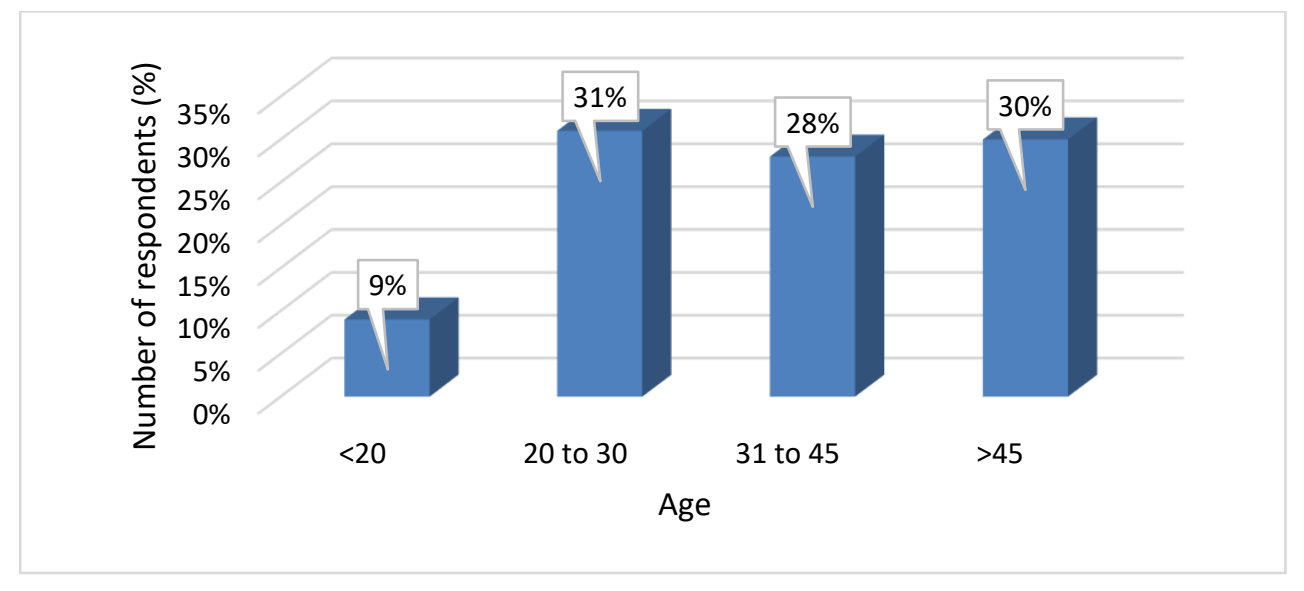

Figure 1. Percentage representation of the age groups of respondents

Source: Authors' own research.

According to Figure no. 2, female gender predominates with 64 percentage, while the male gender comes with 36 percentage. Gender differences is best accounted when risk perception is considered. Women tend to have a higher perceiving risk than men involving also a higher negative attitude regarding disputable topics, such as nuclear topic (Stefanelli et al., 2017). Women risk perception is influenced by biological and educational factors as maternity or low technical background (Nguyen and Yim, 2018; D.J. Davidson, and W.R. Freudenburg, 1996). However, not all studies demonstrate the idea that gender have a direct effect on behaviors and attitudes regarding nuclear topics. 
At the same time all respondents are coming mostly from urban areas. Demographic and social characteristics are direct correlated with the level of public acceptance.

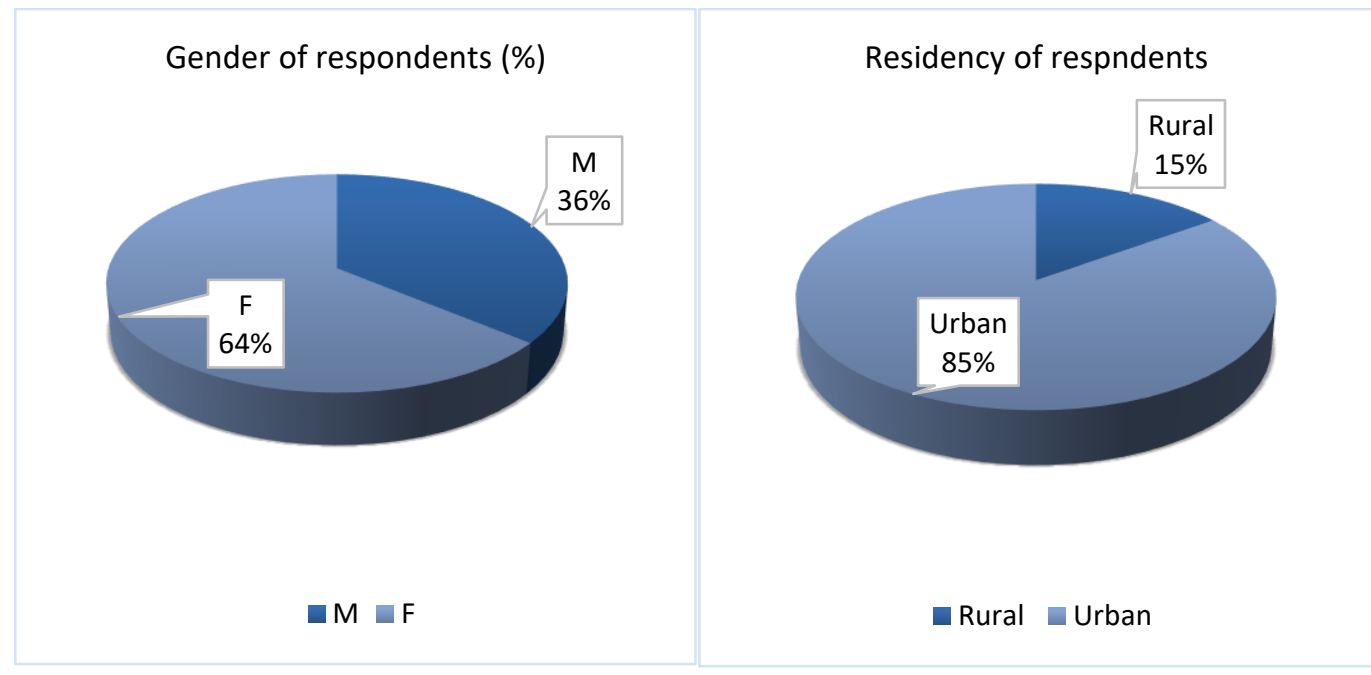

a)

b)

Figure 2. Percentage representation of the respondents'

a) gender

b) residency area

Source: Authors' own research.

Figure no. 3 comprises two graphs related with respondents work experience and their position at the workplace. The majority of respondents are employees, $65 \%$ of the respondents, and their experience is higher than 5 years. Decision makings persons account only small percentages, while other category, the second category in terms of number of respondents is composed mainly of students or retired persons.

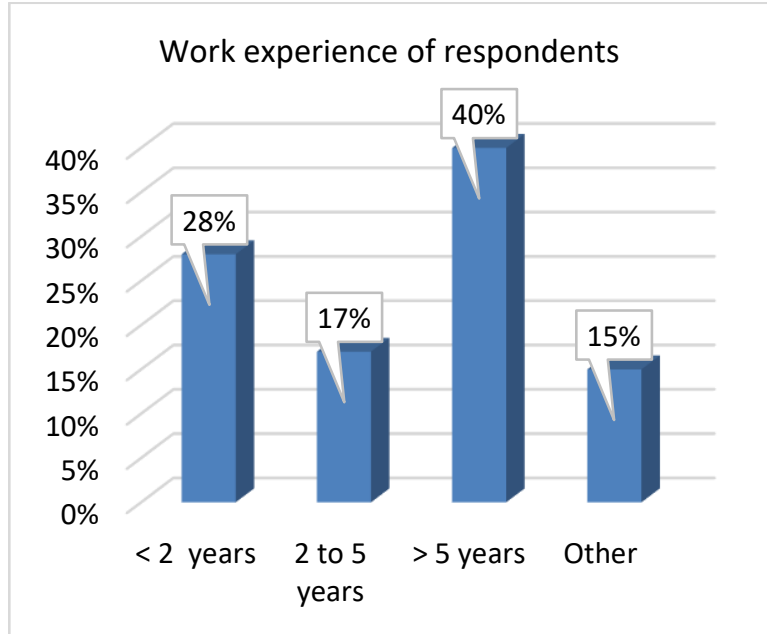

a)

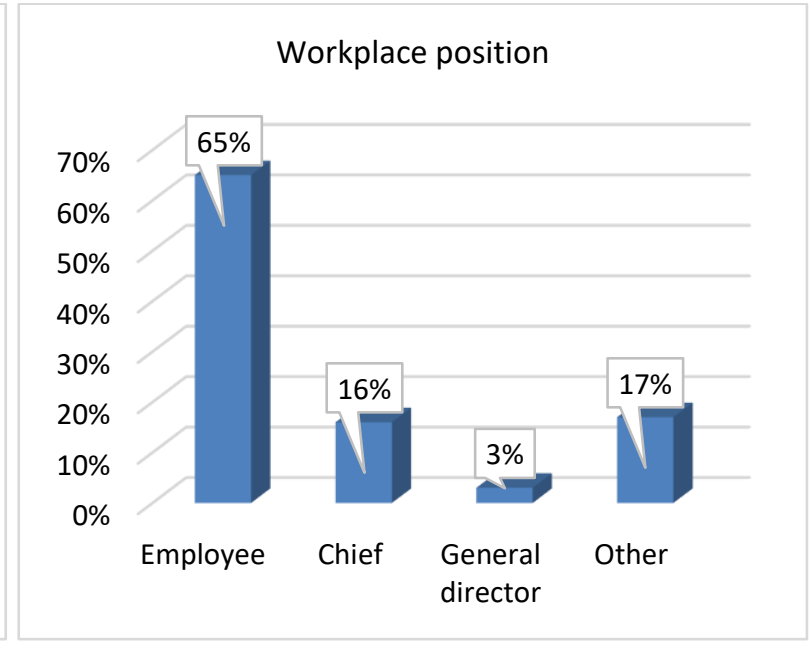

b)

PICBE $\mid 5$

Figure 3. Percentage representation of the respondents'

a) work experience

b) workplace position

Source: Authors' own research. 
As Figure no. 4 shows, respondents are working mostly in Education (19\%), Provision of Services (15\%) or Manufacture (15\%), but a high rate was also observed in Other category which consisted of different fields, e.g. universities, research centers, transportation sector or international companies.

Studies in this field revealed that respondents' attitudes to nuclear energy depend on their level of knowledge and expertise.

PICBE | 6

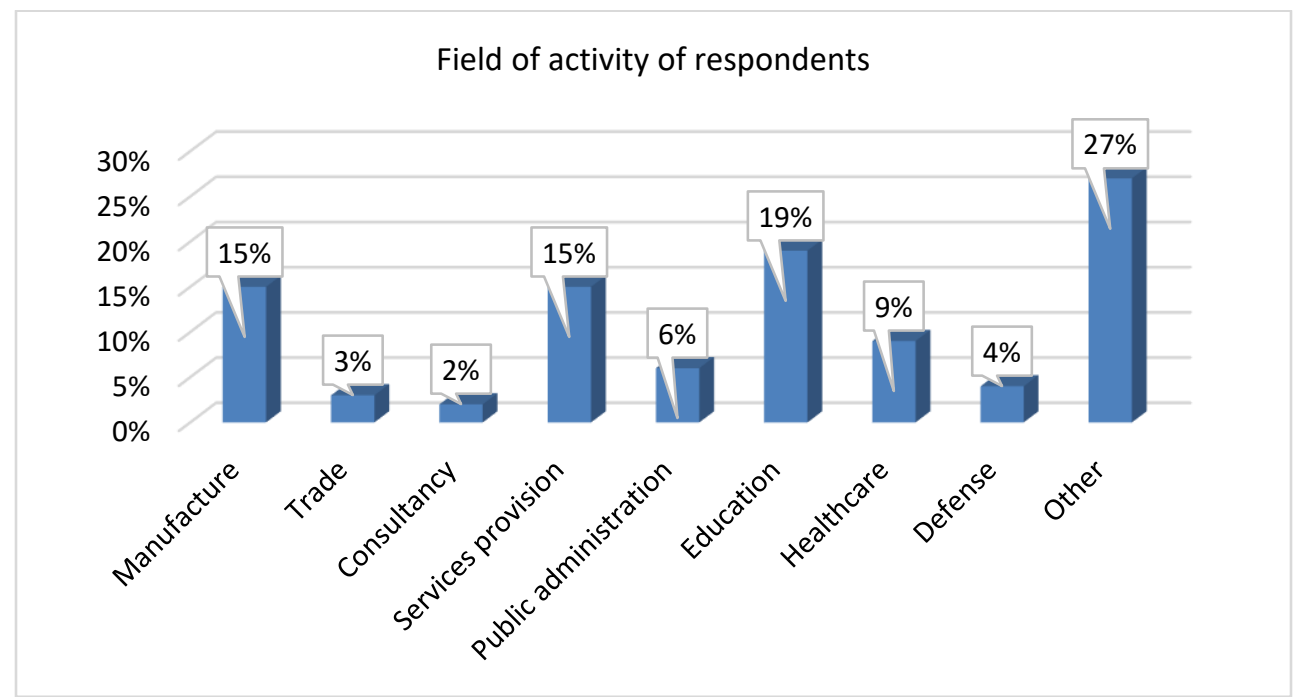

Figure 4. Percentage representation of the respondents' field of activity

Source: Authors' own research.

Furthermore, the study revealed an important aspect related with the degree of acceptance of nuclear energy as an electricity generating source. If they prefer or not nuclear energy is important when radioactive waste disposal facility is considered. At the same time, through this question public acceptance could be measured, a decisive factor for such analysis.

It is paramount to discuss the value of $37 \%$ attributed to the fact that people would opt for alternative methods for electricity generation because. On the other hand, $25 \%$, respectively $29 \%$ of respondents were shown to be in favor or somewhat in favor of nuclear energy (Figure no. 5). These results suggest that questionnaire participants are almost differentiated into two groups, those accepting nuclear energy as electricity source and those which prefer alternative methods for electricity generation.

Our research questionnaire has sown that only $1 \%$ of the respondents strongly oppose nuclear energy, adding to this that $7 \%$ rather oppose. 


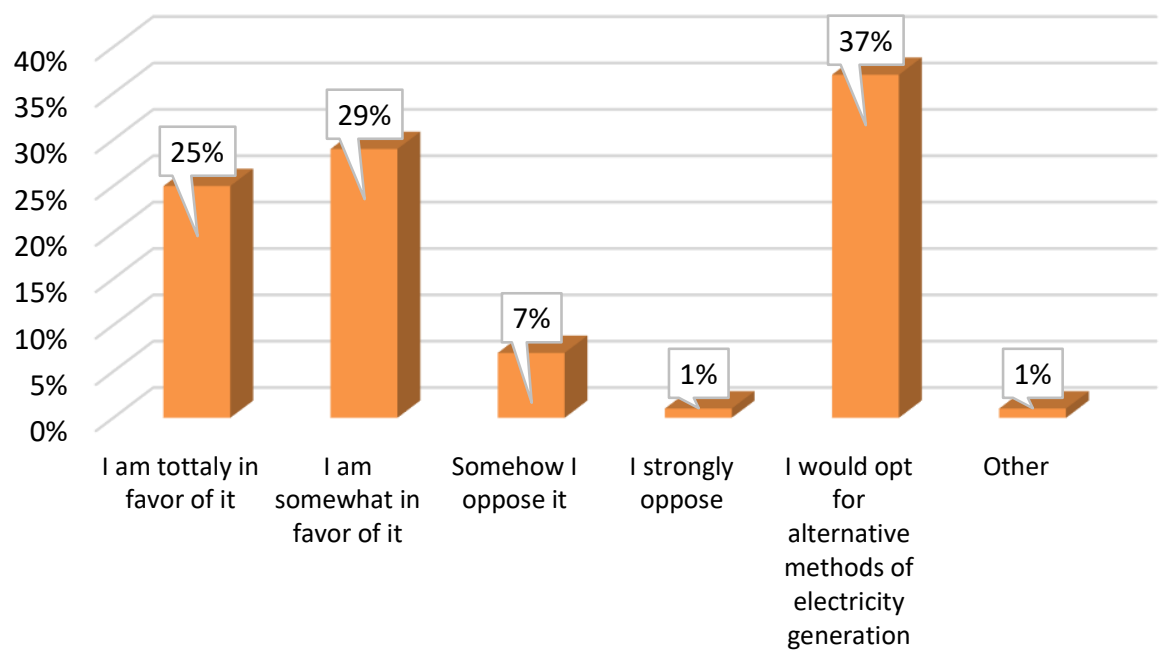

PICBE $\mid 7$

Figure 5. Percentage representation of the respondents' level of acceptance regarding nuclear energy as an electricity generating source

Source: Authors' own research.

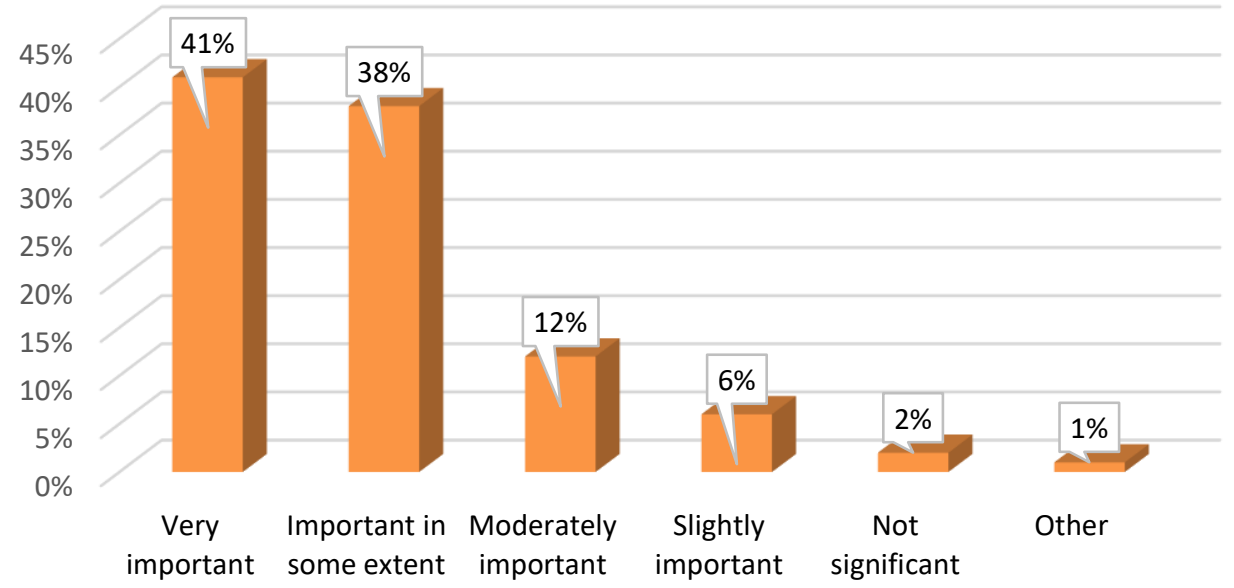

Figure 6. Nuclear energy and its importance in meeting the electricity needs in the next decades

Source: Authors' own research.

It is curiously to find that people give importance to nuclear energy when the need for electricity in the next decades is discussed (Figure no. 6). Public attitude on nuclear energy is drastically changed in this case. A wide discussion could be opened on this issue. People could be worried about the energy security. Securing energy supply by using nuclear energy represent an important fact that sustainable development is achievable. Nuclear power is also a crucial part of the future low-carbon electricity system and this result helps the researchers to see where the future potential is.

The level of information and knowledge regarding the radioactive waste management, disposal plans, programs, and policies is closely in the middle on the Likert scale which shows that respondents have an interest in the subject of nuclear technology. 
Education and enough level of knowledge influence the acceptance of nuclear energy and people tend to have a more affirmative opinion about nuclear energy, as numerous studies have shown (Slovic, 1999, Flynn et.al, 1994, Harris et. al, 2018).

Our study indicates that $47 \%$ of respondents feel informed to some extent, as Figure no.7 is showing. Figure no. 8 reveal that respondents have a decreased level of information related with radioactive waste as can be seen from the three groups of respondents, each group being composed of around $30 \%$ of the respondents. All these issues conduct to the idea that respondents' attitude to nuclear energy and radioactive waste is shaped under different conditions according to their own conscience and not according to their knowledge.

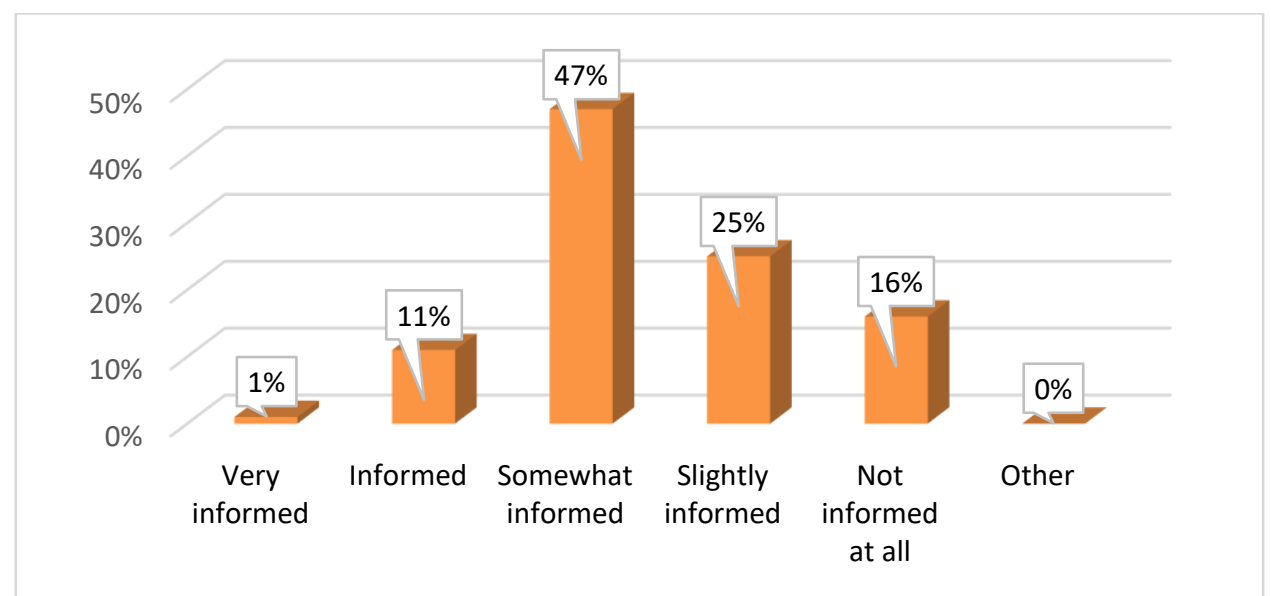

Figure 7. Percentage representation of the degree of citizens informing regarding the management and disposal of radioactive waste

Source: Authors' own research.

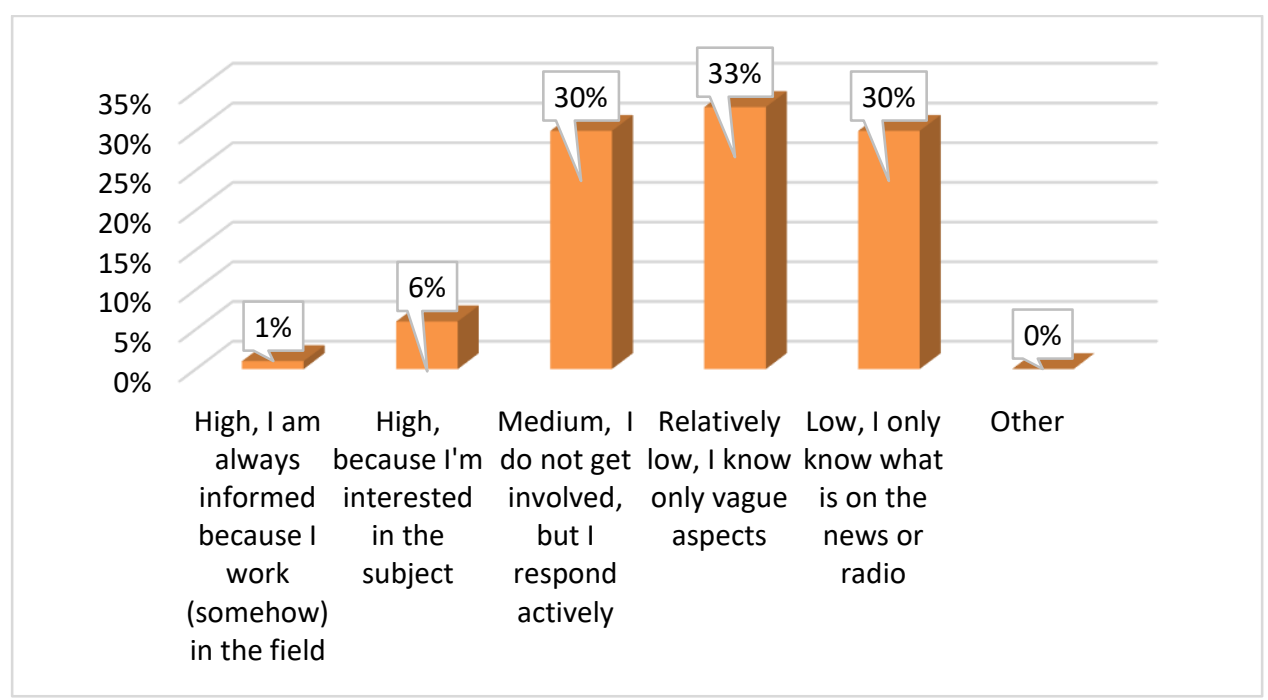

Figure 8. Percentage representation of the respondents' level of knowledge regarding radioactive waste plans, programs and policies

Source: Authors' own research.

Regarding the willingness for cooperation of respondents, Figures no. 9 shows a huge discrepancy between the perceived benefits and the public acceptance with $36 \%$ of respondents 
saying that they don't agree with such a facility in any area while only $7 \%$ saying that they will accept to cooperate with the responsible stakeholders if they are rewarded. Here, NIMBY phenomenon is emphasized because most of the respondents oppose and, more than that, refuse cooperation and other benefits just to not have a nuclear facility in their backyard.

In support of these results, comes the results represented in Figures no. 10 where is represented the predilection of respondents for accepting a radioactive waste repository around settlements. As this graph shows, $62 \%$ of respondents do not agree with such a facility in the area of living of people. Only small percentages of respondents will accept different benefits (e.g. shares, jobs, financial compensations or economic development for the area) in exchange for the location of a radioactive waste repository. Respondents were neither motivated by a) shares within the companies, $b$ ) attractive jobs to the locals, c) financial compensations nor $d$ ) economic and social development of the respective area, but they placed themselves in the category e) I do not agree with the location of such a repository near human settlements.

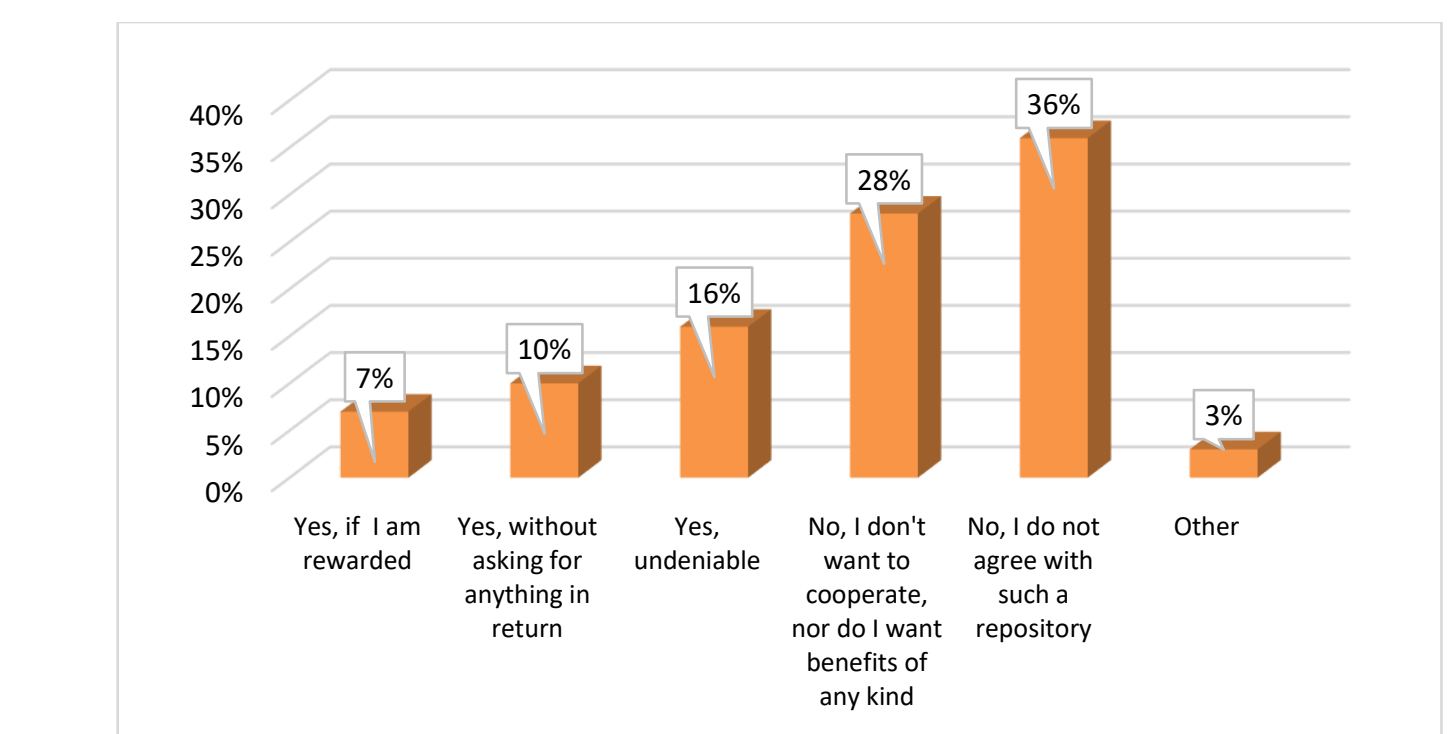

PICBE $\mid 9$ Figure 9. Percentage representation of the respondents' willingness regarding the cooperation
with parties involved in building of a repository

Source: Authors' own research. 


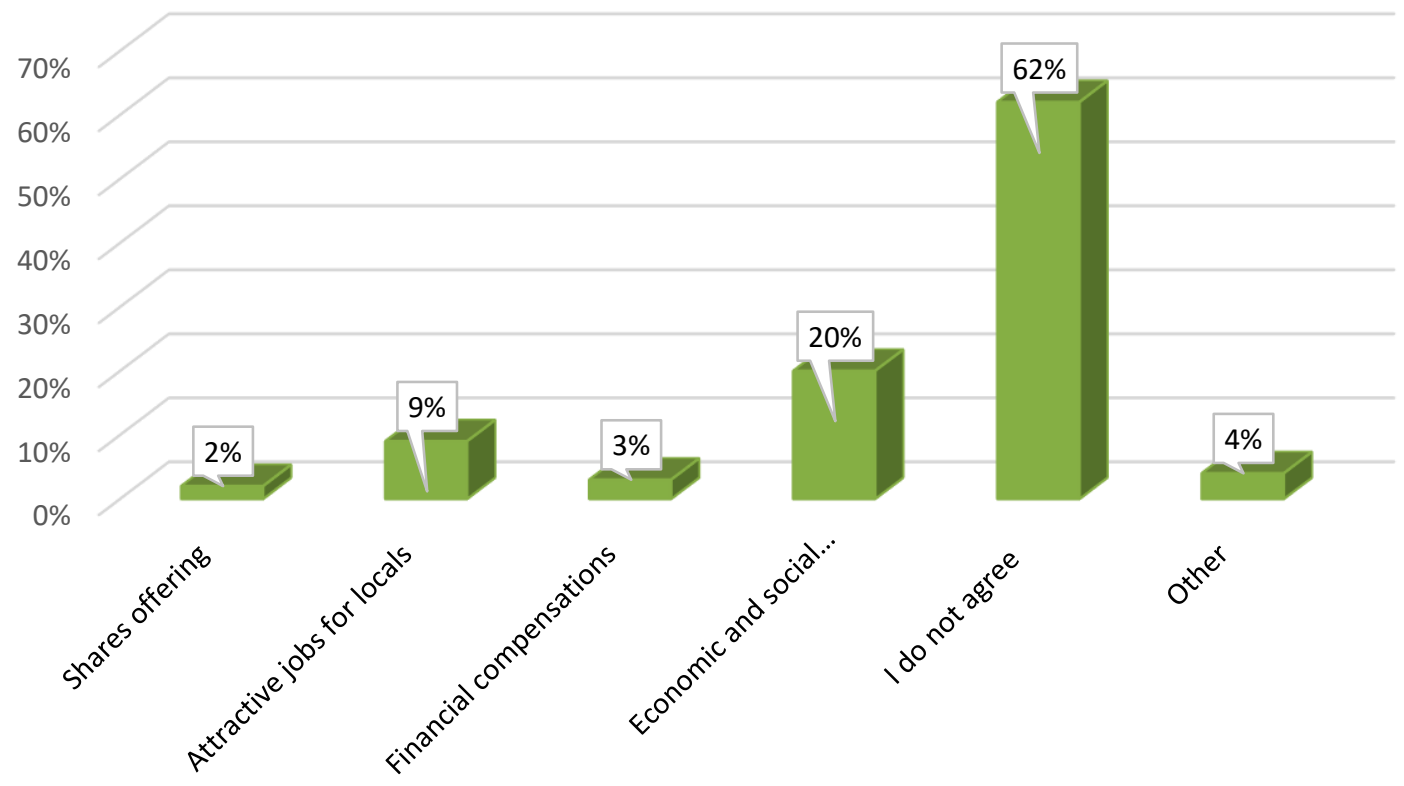

PICBE $\mid 10$

Figure 10. Percentage representation of the respondents' predilection for the location of a radioactive waste repository

Source: Authors' own research.

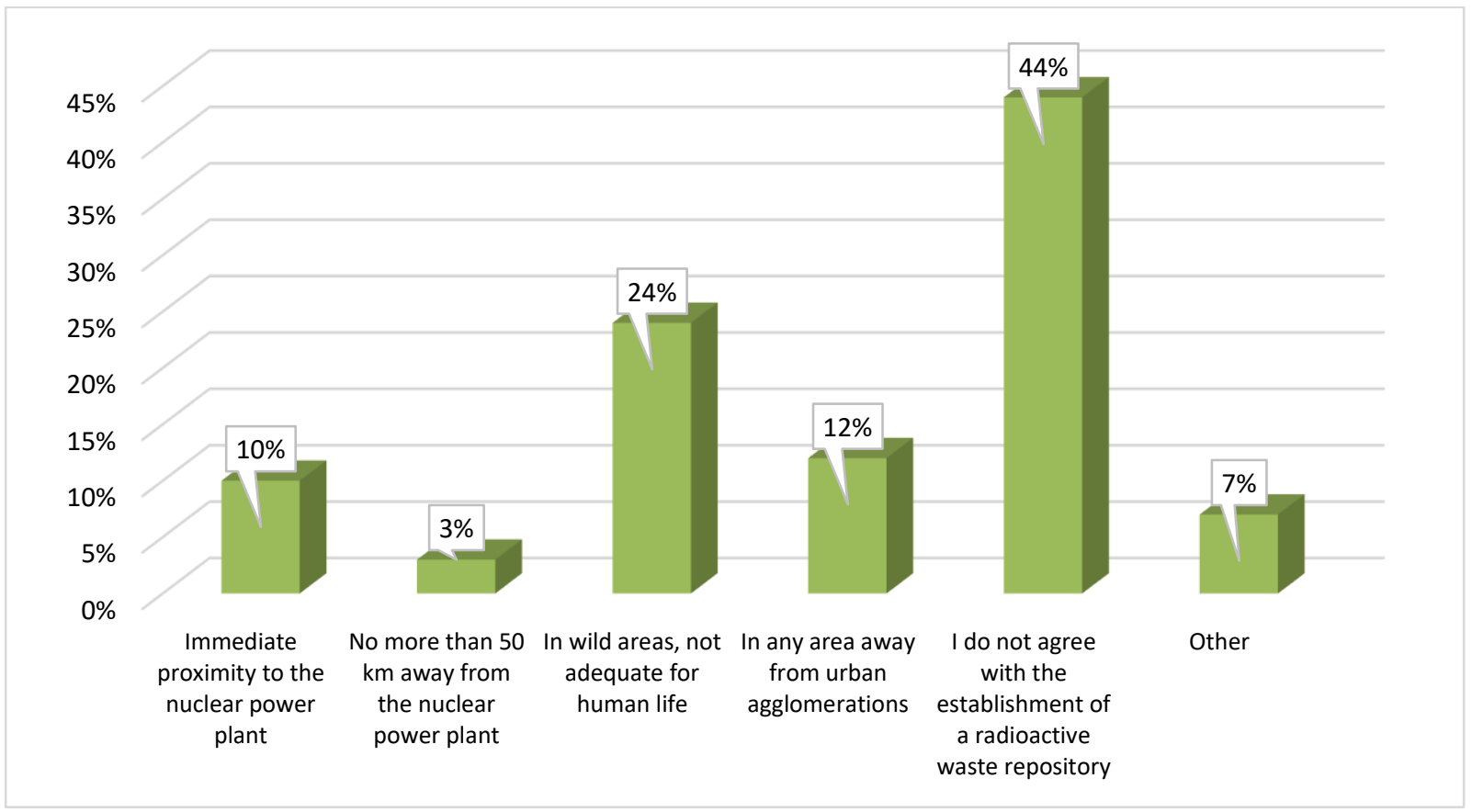

Figure 11. Percentage representation of the respondents' concern about the impacts of a radioactive waste repository

Source: Authors' own research. 
Respondents, in proportion of $44 \%$, have a negative view regarding the establishment of a radioactive waste repository in their territory, and a positive view when wild areas which are not suitable for the human life are considered for the repository location, 24\%, as Figure no. 11 shows.

The represented graph in Figure no. 12 shows that 55\% of respondents are concerned that such a repository would lead to an overall damage, as vegetation and wildlife with repercussions on citizens, result confirmed also by other studies (Flynn, 1994).

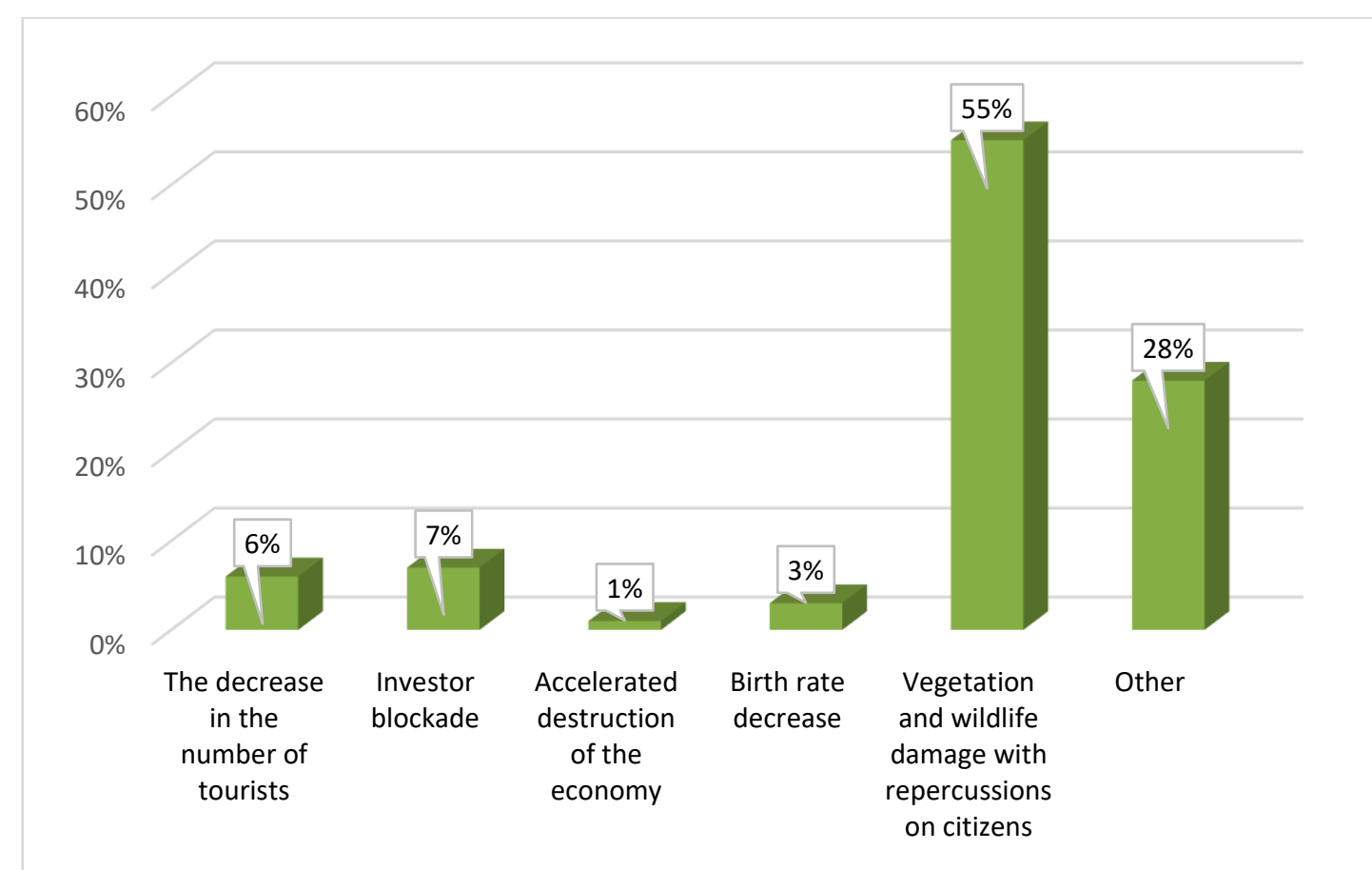

Figure 12. Representation of respondents' opinion percentage regarding the repercussions of locating a permanent radioactive waste repository

Source: Authors' own research. 


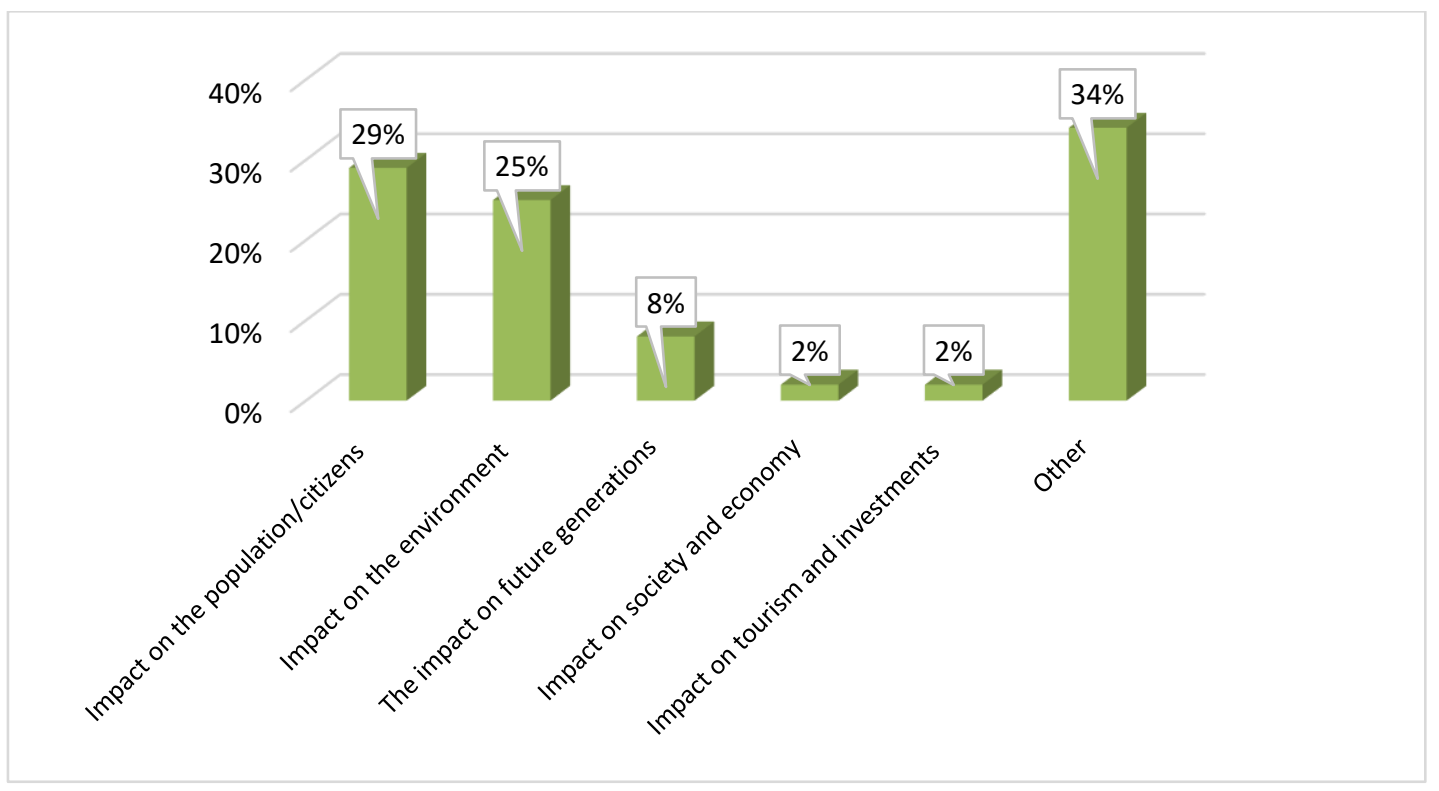

Figure 13. Representation of respondents' opinion percentage regarding the aspects which they consider important when public informing by involved parties is considered

Source: Authors' own research.

Figure no. 13 shows that impact on humans is the most discussed topic between stakeholders. The results showed in Figures no. 12 and no. 13 are good indicators of severity of consequences regarding the emplacement of a radioactive waste repository, as respondents perceive the risks associated with positioning of a nuclear facility in their backyard.

Depending on their beliefs, but with a huge consideration to the health risk, many respondents have shown worry regarding the negative impact on birthrate and negative impact on the economy.

Literature studies emphasize that social and economic factors contribute to the public acceptance of nuclear energy (Nguyen and Yim, 2018).

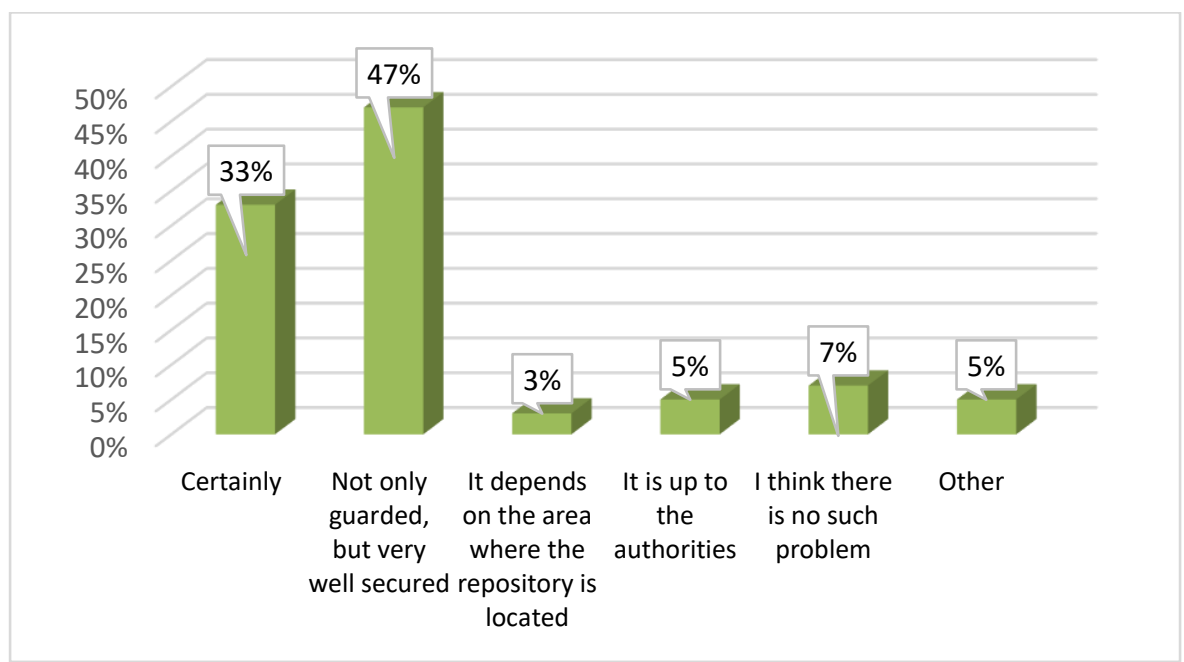

Figure 14. Representation of respondents' opinion percentage regarding the need on for additional security applied to a repository so as not to be subjected to a terrorist attack

Source: Authors' own research. 
From Figure no. 14 it is clearly that mostly of the respondents are worried by the potential terrorist attacks. Respondents, in proportion of $33 \%$ affirmed that certainly a radioactive waste repository must be guarded, and a higher percentage of respondents believe that such repository require not only additional guard, but also security measures applied.

Research studies in the field indicated that terrorism is one of the nuclear hazards which can conduct to potential nuclear accidents (Hirsch et al., 2005).

The representation from Figure no. 15 shows that respondents are not passive in terms of nuclear energy. Around 30\% of respondents, think that involved parties responsible for public information must have available their contact data. Such kind of availability will surely increase the confidence of people in nuclear energy.

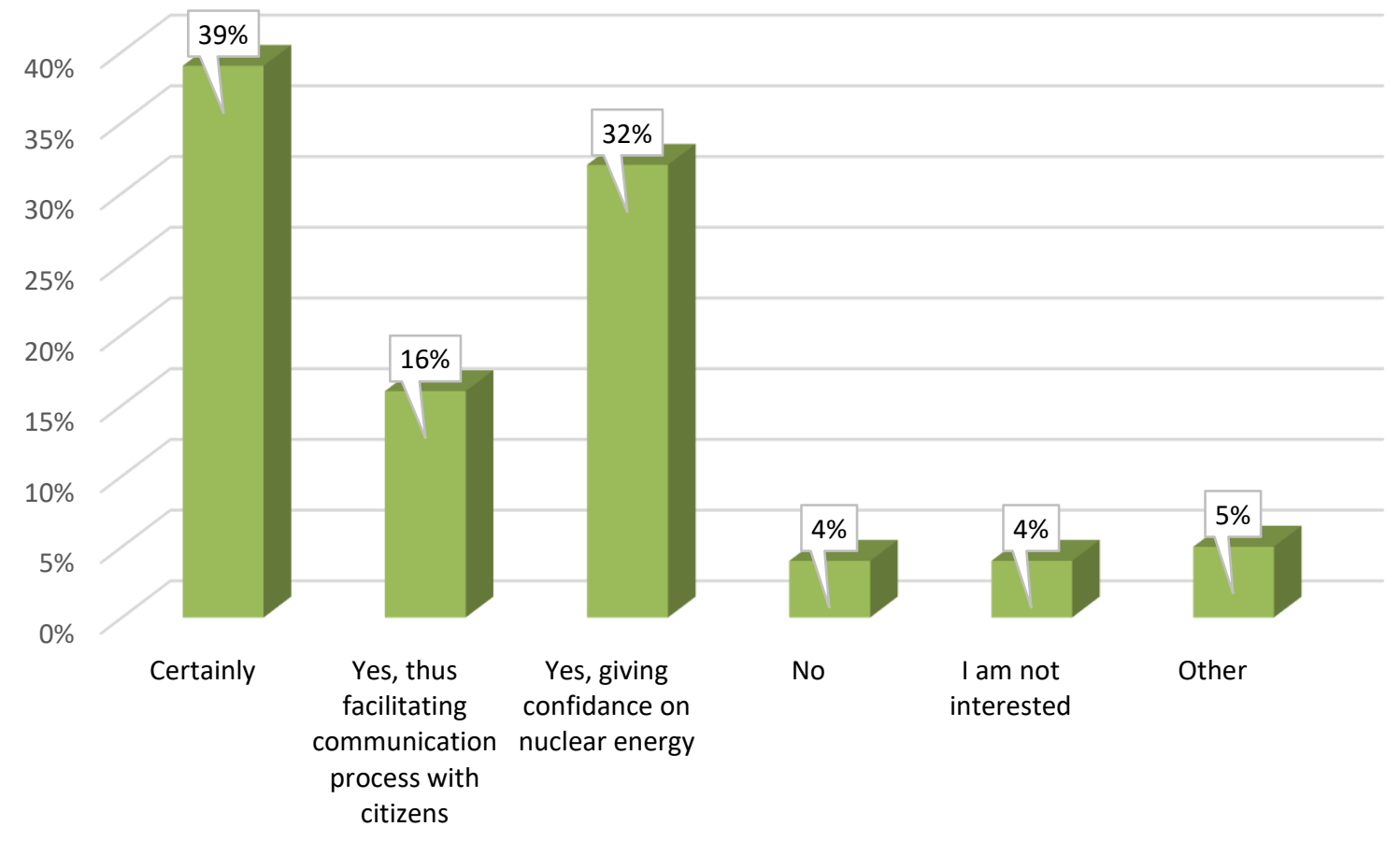

Figure 15. Representation of respondents' desire percentage regarding the availability of contact data of persons responsible for informing the public

Source: Authors' own research.

\section{Conclusion}

This study investigated the attitudes of respondents with respect to nuclear energy and radioactive waste disposal. People's attitudes influence decisions regarding the location of a radioactive waste disposal.

Important key factors affecting disposal of radioactive waste in the sustainable development approach were addressed in this paper, such as perceived affective quality of respondents images, perceived knowledge, perceived attitudes, social, psychological and economic support or opposition, perceived harm, risk perception, as well as opinions and attitudes to nuclear technology.

Based on this research the main determinants which contribute to the location of a radioactive waste disposal were identified. Arguing that professionals show a much positive 
attitude with regard to nuclear energy, their beliefs could influence the stakeholder's decisions. Majority of questionnaire respondents have a high educational background and are involved in the services or manufacture field. The highest percentage of respondents were women. The level of their information and knowledge was determined to be in at the middle of a Likert scale. In terms of nuclear energy, they feel somehow informed or they know only the information which is available to the large public.

PICBE $\mid 14$

In some circumstances, respondents have shown a greater openness to alternative methods of electricity generation, to the detriment of nuclear energy. It is true that not far from this result were positioned also the respondents, which have a positive attitude in favor of nuclear energy. The tendency in which respondents favor nuclear energy was identified throughout the questionnaire, because the respondents reported a positive attitude regarding nuclear energy if is considered for electricity generation now and for other future commercial applications.

The most dramatic view was identified when radioactive waste disposal topic was brought into discussion. So that, respondents indicated that they do not agree with a radioactive waste repository near the human living areas, or near their settlements, emphasizing the NIMBY phenomenon. It was found that wild areas, which are not adequate for human life, far from living agglomerations are most suitable places for these needs.

The study has shown that the highest concern refers to the impact of radioactive waste, which is considered to be increased over the population, citizens, but also over the environment. As was discussed in the Introduction, the main risk factor associated with the radioactive waste is the human risk and another specific factor related to the risk of disposal of radioactive waste is the environmental risk.

Nuclear energy is also exposed to terrorists' attacks creating worry for the population, as was found in the literature and confirmed by this study. Respondents agreed that radioactive waste repositories must be guarded and very well secured to decrease or even to block the possibility of malicious attacks.

Stakeholders should take seriously the idea of public information and available contacts because respondents are open to cooperate and collaborate, as it was identified in this study. Dispensable contact data will increase the confidence in nuclear energy for a beneficial use now and in the future.

\section{References}

Beken T., Dorn N., Van Daele S. (2010). Security risks in nuclear waste management: Exceptionalism, opaqueness and vulnerability. Journal of Environmental Management, 91, 940-948.

Choi S., Nam H., Ko W. (2016). Environmental life cycle risk modeling of nuclear waste recycling systems, Energy, 112, 836-851.

Davidson D.J., Freudenburg W.R. (1996). Gender and environmental risk concern - a review and analysis of available research. Environmental Behaviour, 28, 302-339. Retrieved from http://dx.doi.org/10.1177/0013916596283003.

Devine-Wright P. (2011). Public engagement with large-scale renewable energy technologies: Breaking the cycle of NIMBYism. Wiley Interdisciplinary Reviews: Climate Change 2, 1(2011), 19-26.

Flynn J., Slovic P., Mertz C.K. (1994). Gender, race, and perception of environmental health risks. Risk Anal, 14, 1101-1108. 
Harris J., Hassall M., Muriuki, G., Warnaar-Notschaele C., McFarland E., Ashworth P. (2018). The demographics of nuclear power: Comparing nuclear experts', scientists' and nonscience professionals' views of risks, benefits and values. Energy Research \& Social Science, 46, 29-30. Retrieved from https://doi.org/10.1016/j.erss.2018.05.035.

Hirsch H., Becker O., Schneider M., Froggatt A. (2005). Nuclear reactor hazards. Ongoing dangers of operating nuclear technology in the 21 st century. Report prepared for Greenpeace International, Amsterdam, 128.

Lehtonen M., Kojo M., Jartti T., Litmanen T., Kari M. (2020). The roles of the state and social licence to operate? Lessons from nuclear waste management in Finland, France, and Sweden. Energy Research \& Social Science, 61.

Moser C., Stauffacher M., Smieszek T., Seidl R., Krütli P., Scholz R. (2013). Psychological factors in discounting negative impacts of nuclear waste. Journal of Environmental Psychology, 35, 121-131.

Nguyen V.P., Yim M.-S. (2018). Examination of different socioeconomic factors that contribute to the public acceptance of nuclear energy. Nuclear Engineering and Technology, 50(5), 767-772. Retrieved from https://doi.org/10.1016/j.net.2018.02.005.

Ramana M. (2013). Shifting strategies and precarious progress: Nuclear waste management in Canada, Energy Policy, 61, 196-206.

Rempe N. (2007). Permanent underground repositories for radioactive waste. Progress in Nuclear Energy, 49 (5), 365-374. Retrieved from http://dx.doi.org/10.1016/j.pnucene.2007.04.002.

Segelod E. (2006). The cost of the Swedish nuclear waste program. Progress in Nuclear Energy, 48, 314-324.

Slovic P. (1999). Trust, emotion, sex, politics, and science: surveying the risk-assessment battlefield. Risk Anal, 19, 689-701.

Stefanelli A., Seidl., Siegrist M. (2017). The discursive politics of nuclear waste: Rethinking participatory approaches and public perceptions over nuclear waste storage repositories in Switzerland. Energy Research \& Social Science, 34, 72-81.

Streimikiene D. (2012). Comparison of carbon dioxide and nuclear waste storage costs in Lithuania. Renewable and Sustainable Energy Reviews, 16, 2434-2445.

Yano K., Mao K., Wharry J., Porterfield M. (2018). Investing in a permanent and sustainable nuclear waste disposal solution. Progress in Nuclear Energy, 108, 474-479. 